\title{
Optimal PAM Control for a Buck Boost DC-DC Converter with a Wide-Speed-Range of Operation for a PMSM
}

\author{
Abdul Motin Howlader ${ }^{\dagger}$, Naomitsu Urasaki*, Tomonobu Senjyu*, Atsushi Yona*, and Ahmed Yousuf Saber** \\ $\dagger *$ Dept. of Electrical and Electronics Eng., University of the Ryukyus, Okinawa, Japan \\ ** Dept. of Electrical and Computer Eng., Missouri University of Sci. and Tech., Rolla, Missouri, USA
}

\begin{abstract}
A pulse width modulation-voltage source inverter (PWM-VSI) is used for variable speed permanent magnet synchronous motor (PMSM) drives. The PWM-VSI fed PMSM has two major disadvantages. Firstly, the PWM-VSI DC-link voltage limits the magnitude of the PMSM terminal voltage. As a result, the motor speed is restricted. Secondly, in a low speed range, the PWM-VSI modulation index declines. This is caused by a high DC-link voltage and a low terminal voltage ratio. As a result, the distortion of the voltage command and the stator current are increased. This paper proposes an optimal pulse amplitude modulation (PAM) control which can adjust the inverter DC-link voltage by using a buck-boost DC-DC converter. At a low speed range, the proposed system can reduce the distortion of the voltage command, which improves the stator current waveform. Also, the allowable speed range is extended. In order to verify the proposed method, experimental results are provided to confirm the simulation results.
\end{abstract}

Key Words: Buck boost DC-DC converter, PAM control, PMSM drive

\section{INTRODUCTION}

In recent years, variable speed controlled permanent magnet synchronous motors (PMSMs) have been developed by evolving power electronics technology and by utilizing rare-earth magnets. PMSMs are widely applied in industry due to their high energy density, high torque to ampere ratio, robustness and high efficiency. A PMSM does not required rotor winding. As a result, the performance of PMSMs is better than induction motors [1].

Generally, PWM voltage source inverters (PWM-VSI) have been used for variable speed PMSM drives [2]-[4]. However, PWM-VSI fed PMSMs have two main disadvantages. Firstly, the PWM-VSI DC-link voltage limits the magnitude of the PMSM terminal voltage. Consequently, the motor speed is also limited because it is necessary for the terminal voltage to be increased proportional to the motor speed. In order to overcome this problem, flux-weakening control [5], [6] or boosting [7] the PWM-VSI DC-link voltage according to the motor driving conditions have been proposed. Secondly, in a low speed range, the PWM-VSI modulation index decreases due to a high DC-link voltage and a low terminal voltage ratio. This problem causes distortion in the stator currents and produces torque. As a result the speed control performance deteriorates.

\footnotetext{
Manuscript received Dec. 1, 2009; revised Jun. 30, 2010

$\dagger$ Corresponding Author: k088477@eve.u-ryukyu.ac.jp

Tel: +81-836-85-9472, Fax: +81-836-85-9401, Ryukyus Univ.

* Dept. of Electrical and Electronics Eng., Ryukyus Univ., Japan

** Dept. of Electrical and Computer Eng., Missouri Univ., USA
}

So far, for control performance in a low speed range, it seems that there are few approaches which focus on the PWM-VSI DC-link voltage. Improving these disadvantages is important in applications that require high performance in a wide speed range, such as electrical vehicles (EVs) [8].

This paper proposes an optimal PAM control system for PMSMs, in order to overcome the above disadvantages. Furthermore, the proposed system allows for a bi-directional energy flow. The system has a bi-directional buck boost DCDC converter [9] on the primary side of the PWM-VSI. This paper also describes the determination of an optimal DC-link voltage command and the duty factors of the converter.

The bi-directional buck-boost DC-DC converter adjusts the motor DC-link voltage with respect to the speed of the motor. As a result, it generates a variable DC-link voltage instead of a constant DC-link voltage at the side of the PWM-VSI. The effectiveness of the proposed method is verified by simulation and experimental results. This paper is organized as follows. In Section II, an optimal DC-link voltage is considered. Section III roughly explain the operating principle of the bi-directional buck boost DC-DC converter. The proposed system is shown in Section IV. This section also explains the switching control of the DC-DC converter. The simulation and experimental results are presented in Section $\mathrm{V}$ and Section VI shows the conclusions. 


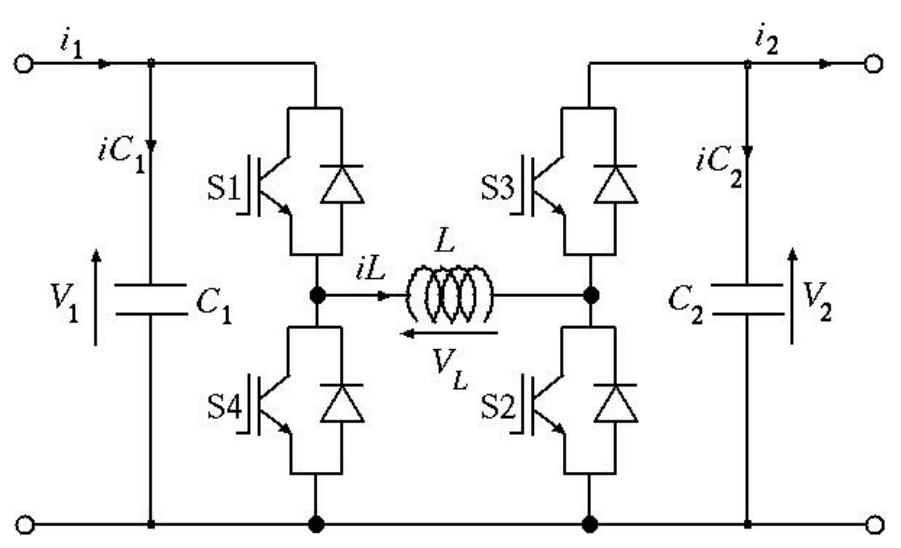

Fig. 1. Bi-directional buck boost DC-DC converter.

\section{DETERMINATION OF THE OPTIMAL DC-LINK VOLTAGE COMMAND}

The PMSM terminal voltage $V_{l}$ is expressed as:

$$
V_{l}=\sqrt{\frac{3}{2}} V_{a m p}
$$

where $V_{a m p}$ is the amplitude of the phase voltage. Since $V_{a m p}=V_{D C} / 2$ in the triangular wave comparison method, $V_{l}$ is imposed following a constraint by the DC-link voltage VDC:

$$
V_{l} \leq \sqrt{\frac{3}{8}} V_{D C}
$$

In order to make PMSMs drive in the constant torque region, $V_{D C}$ should be determined so that $V_{l}$ does not exceed its constraint. However, too large a $V_{D C}$ reduces the PWM-VSI modulation index and then, it is difficult for the PWM-VSI to realize the required phase voltages.

Further, the disturbance voltage related to the dead time of the switching devices increases in operation with a low modulation index. In order to maintain the maximum modulation index and the minimum disturbance voltages in any speed range, it is necessary for $V_{D C}$ to maintain an optimal value. Therefore, the commanded DC-link voltage $V_{D C}^{*}$ is calculated as follows, after calculation of the commanded d-q axis voltages:

$$
V_{D C}^{*} \leq \sqrt{\frac{8}{3}} V_{l}^{*}
$$

By the above calculation, $V_{D C}^{*}$ is determined on-line according to $V_{l}^{*}$, and it can correspond to the load variation. It is important that $V_{l}$ be greater than the nominal value because the PWM-VSI output voltage includes harmonic components due to several nonlinearities of the PWM-VSI. Furthermore, a boost voltage is required for it to start up stably. Therefore, $V_{D C}^{*}$ is finally determined as follows:

$$
V_{D C}^{*}=\max \left(K_{P A M} V_{l}^{*}, V_{D C \text { min }}\right)
$$

where $K_{P A M}$ and $V_{D C \text { min }}$ are the PAM coefficient and the lower limit of the DC-link voltage, respectively. In an ideal

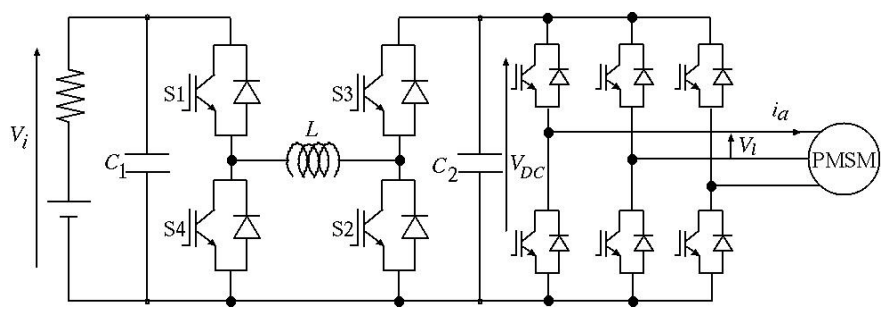

Fig. 2. Variable DC-link voltage circuit.

situation the value of $K_{P A M}$ is $\sqrt{\frac{8}{3}}$ but in order to give a margin, $K_{P A M}$ is selected as 2.5 .

\section{BI-DIRECTIONAL BUCK BOOST DC-DC CONVERTER}

In order to buck and boost the DC-link voltage, the proposed system uses a bi-directional buck-boost DC-DC converter [4] as shown in Fig. 1. The operation of each mode of this converter is presented in [4]. In this converter, the terminal voltages $v_{1}$ and $v_{2}$ are expressed as:

$$
\left.\begin{array}{l}
v_{2}=\frac{D_{1}}{1-D_{2}} v_{1} \\
v_{1}=\frac{D_{3}}{1-D_{4}} v_{2}
\end{array}\right\}
$$

where $D_{i}\{i \in 1,2,3,4\}$ are respectively the duty factors for the switches $S_{i}\{i \in 1,2,3,4\}$. From (4), the bi-directional buck-boost operation can be achieved by using the switches $S_{1}$ and $S_{2}$ when the power flows from $v_{1}$ to $v_{2}$ and by using the switches $S_{3}$ and $S_{4}$ when the power flows from $v_{2}$ to $v_{1}$. The variables in Fig. $1, i_{L}, v_{1}$ and $v_{2}$, are then expressed as the following differential equations:

$$
\left.\begin{array}{c}
i_{L}=\frac{v_{L}}{L} \\
v_{1}=\frac{i_{C 1}}{C_{1}} v_{2} \\
v_{2}=\frac{i_{c 2}}{C_{2}}
\end{array}\right\} .
$$

Note that the variables, $v_{L}, i_{C 1}$ and $i_{C 2}$, are determined according to the switch states and the initial value of $i_{L}$.

\section{OPTIMAL PAM CONTROL}

In this section, a control method for the bi-directional buckboost DC-DC converter will be explained. A variable DC-link voltage circuit is established as shown in Fig. 2 by using the circuit shown in Fig. 1. In this circuit, the input voltage $V_{i}$ and PWM-VSI DC-link voltage VDC correspond to $v_{1}$ and $v_{2}$ in Fig. 1, respectively.

For motoring mode, if $V_{D C}^{*}<V_{i}$ then the duty factors for each switch are determined as:

$$
\left.\begin{array}{c}
D_{1}=\frac{V_{D C}^{*}}{V_{i}} \\
D_{2}=0 \\
D_{3}=0 \\
D_{4}=0
\end{array}\right\} .
$$

The converter outputs the optimal $V_{D C}$ by a step-down operation according to the motor speed. If $V_{D C}^{*}>V_{i}$ for motoring mode, then the duty factors for each switch are determined as: 




Fig. 3. Flowchart of PAM operation.

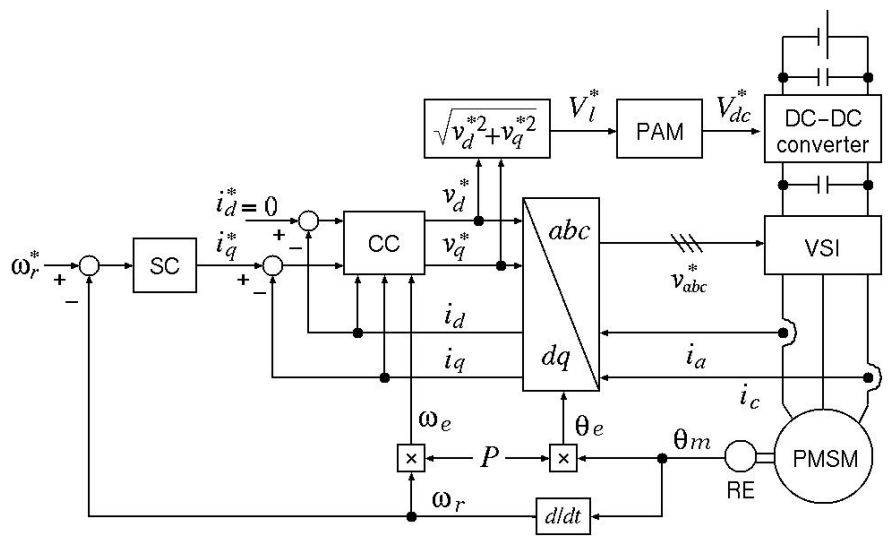

Fig. 4. PAM control system for PMSM drive.

$$
\left.\begin{array}{c}
D_{1}=1 \\
D_{2}=1-\frac{V_{i}}{V_{D C}^{*}} \\
D_{3}=0 \\
D_{4}=0
\end{array}\right\} .
$$

In this case, the converter performs a step-up operation according to the motor speed.

For regenerative mode, the battery charge current is controlled by boosting up $V_{D C}$ to over $V_{i}$. If $V_{D C}^{*}<V_{i}$ for the regenerative mode, the duty factors for each switch will be determined as:

$$
\left.\begin{array}{c}
D_{1}=0 \\
D_{2}=0 \\
D_{3}=1 \\
D_{4}=1-\frac{V_{D C}^{*}}{V_{i}}
\end{array}\right\} .
$$

If $V_{D C}^{*}>V_{i}$ for the regenerative mode, the duty factors for each switch will be determined as:

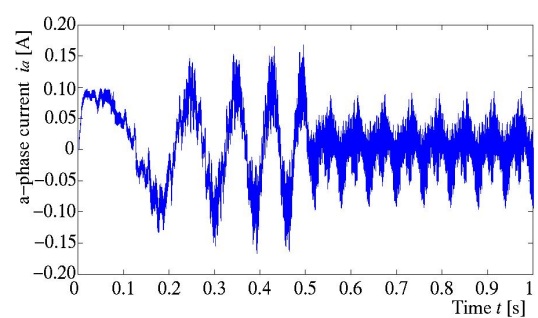

(a)

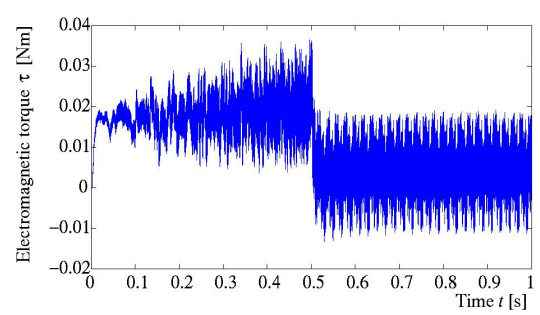

(b)



(c)

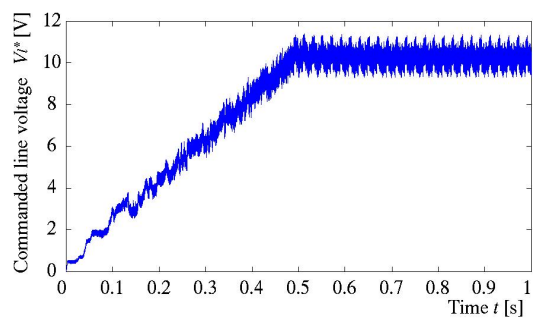

(d)

Fig. 5. Simulation results: low speed operation for fixed DC-link voltage $\left(V_{D C}=100 \mathrm{~V}\right)$.

$$
\left.\begin{array}{c}
D_{1}=0 \\
D_{2}=0 \\
D_{3}=\frac{V_{i}}{V_{D C}^{*}} \\
D_{4}=0
\end{array}\right\} .
$$

Fig. 3 shows the gate duty factor and the operation mode of the converter.

\section{SIMULATION AND EXPERIMENTAL RESULTS}

The proposed control system is shown in Fig. 4. The PMSM control system is composed of speed and current control loops, and it assumes that the actual rotor position and the three phase currents can be obtained by a rotary encoder and current sensors [10]. $V_{l}^{*}$ is calculated after the calculation of the commanded dq-axis voltage. Then, using the calculated $V_{l}^{*}$, the DC-DC converter controller determines the duty factors based on Section IV. 




(a)

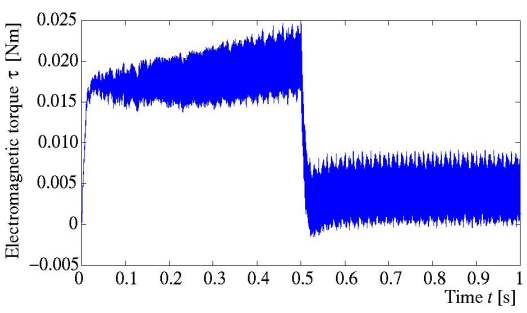

(b)

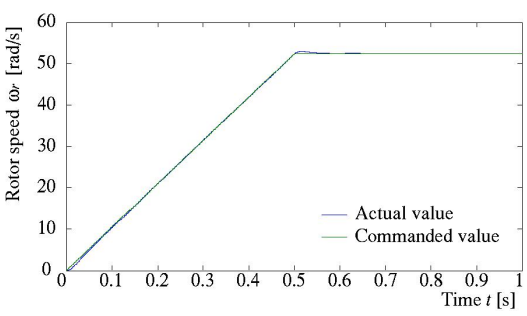

(c)

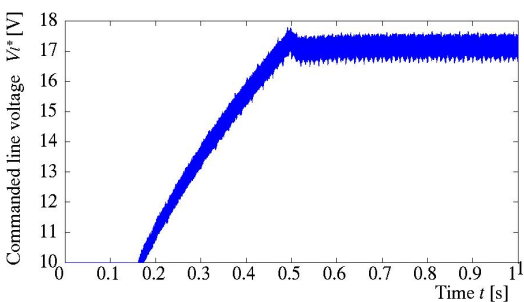

(d)



(e)

Fig. 6. Simulation results: low speed operation for variable DC-link voltage.

In order to verify the proposed system, an optimal PAM control simulation and experiment are carried out for the PMSM whose data is given in Table I. A TMS320C6713-225 CPU is used for this experiment.

Fig. 5 and Fig. 6 show the simulation results for low speed operation. In this simulation, the PMSM is accelerated from 0 to 500rpm. For comparison, the simulation result for fixed DClink voltage operation $\left(V_{D C}=100 \mathrm{~V}\right)$ is shown in Fig. 5. From this figure, the pulsation of the stator current, the pulsation of the torque and the pulsation of the commanded line voltage are

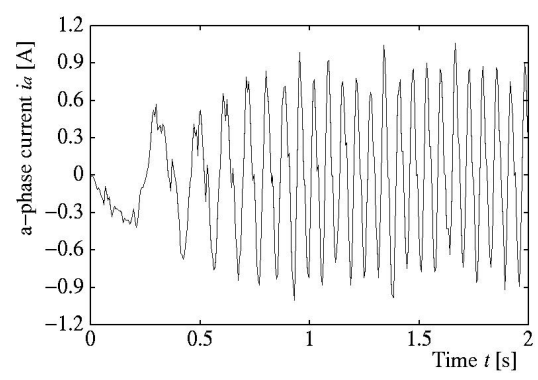

(a)

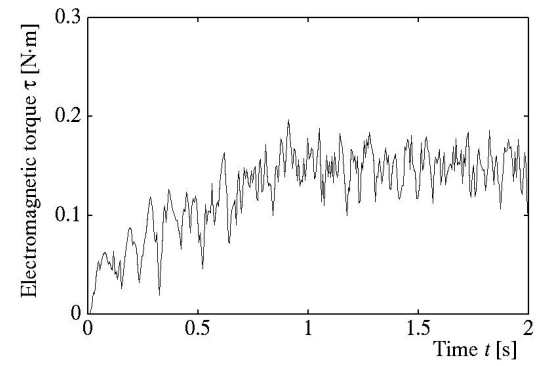

(b)

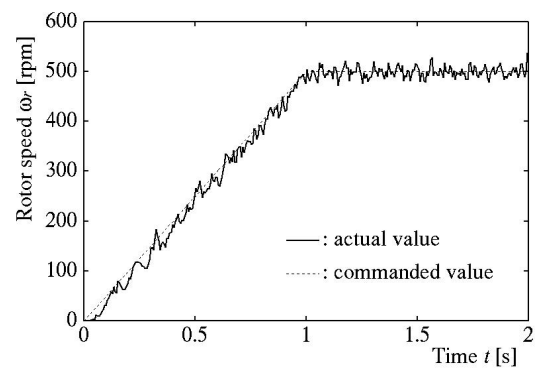

(c)

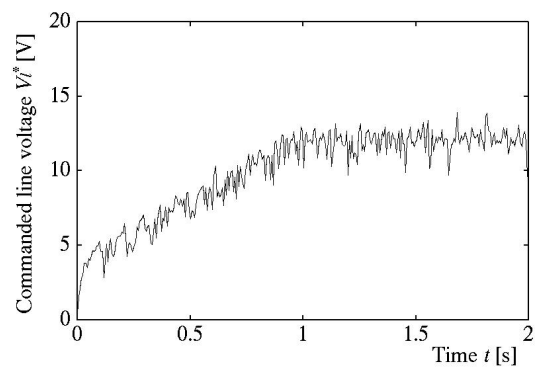

(d)

Fig. 7. Experimental results: low speed operation for fixed DC-link voltage $\left(V_{D C}=100 \mathrm{~V}\right)$

significantly increased. It can be confirmed from Fig. 6 that the desired commanded voltage is produced by the proposed method, and that the distortion of the stator currents, the pulsation of the torque and the pulsation of the commanded line voltage are improved. As a result, the proposed method is shown to have smoother operation than the fixed DC-link voltage operation.

Further, it can be confirmed from the bottom figure of Fig. 6 that the DC-link voltage is controlled according to the driving condition.

Fig. 7 and Fig. 8 show the experimental results for low speed operation. In this experiment, the PMSM is accelerated from 0 to 500rpm. Fixed DC-link voltage operation is shown in 




(a)

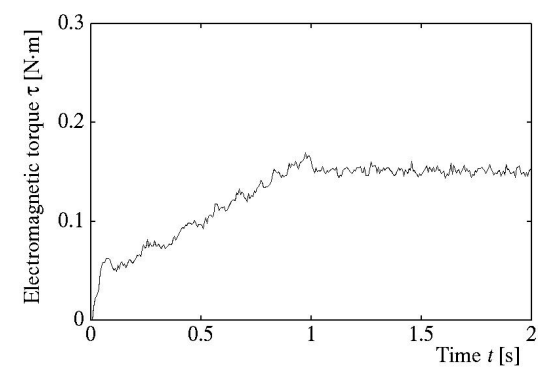

(b)



(c)

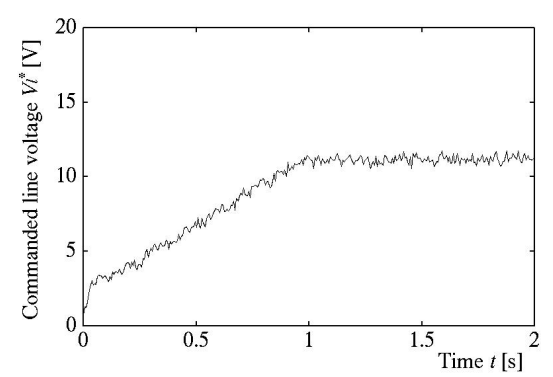

(d)

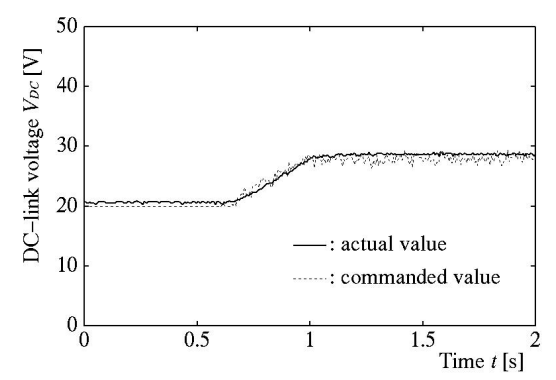

(e)

Fig. 8. Experimental results: low speed operation for variable DC-link voltage.

Fig. 7 and the proposed method (i.e. variable DC-link voltage operation) is shown in Fig. 8. From Fig. 7, the pulsation of the



(a)

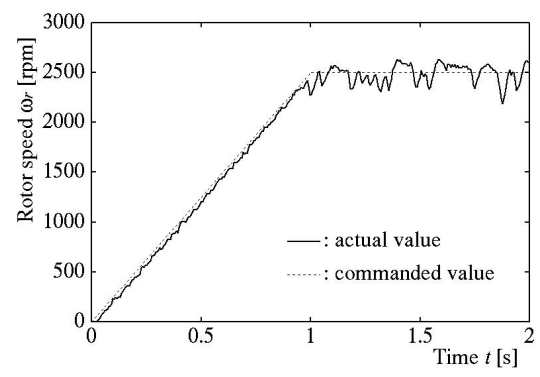

(b)

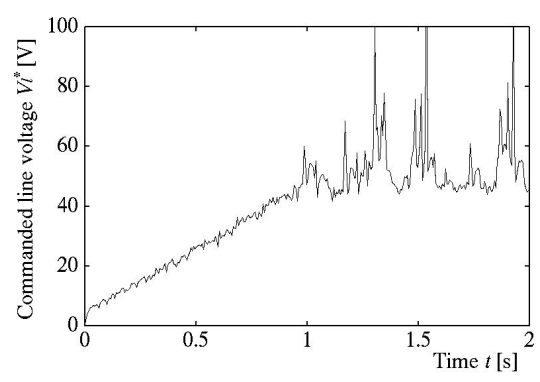

(c)

Fig. 9. Experimental results: high speed operation for fixed DC-link voltage $\left(V_{D C}=100 \mathrm{~V}\right)$.

stator current, the pulsation of the torque and the pulsation of the commanded line voltage are drastically increased. On the other hand, from Fig. 8, the distortion of the stator current, the pulsation of the torque and the pulsation of the commanded line voltage are improved. From the bottom figure of Fig. 8, it can be seen that the DC-link voltage is controlled according to the driving condition.

During low speed, in the case of a fixed voltage the operation of the DC-link voltage is very high and the motor terminal voltage is very low. As a result, the modulation index is decreased and pulsations occur. However, in variable DClink voltage operation, the DC-link voltage is controlled by the Buck Boost DC-DC converter and it maintains the maximum modulation index. This is why, it can generate smooth output. According to the simulation and experimental results, the $a$ phase current is different in the steady state operation of the motor drive. In the simulation, the motor load is zero but in the experiment, the motor is connected to a generator. As a result, some load appears. This is why, there are some differences between the experiment and simulation results.

The experimental results in the high speed range of operation are shown in Fig. 9 and Fig. 10. In this experiment, the PMSM is accelerated from 0 to 2500rpm. Fig. 9 shows the fixed DC-link voltage operation and Fig. 10 shows the 


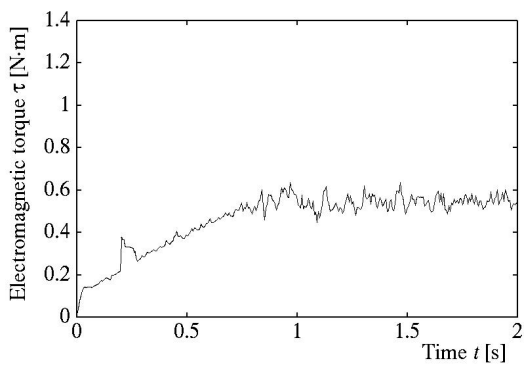

(a)



(b)

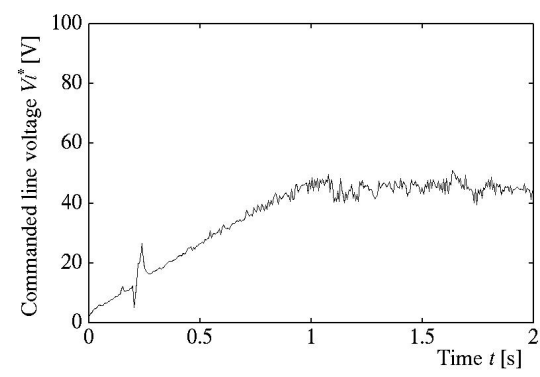

(c)

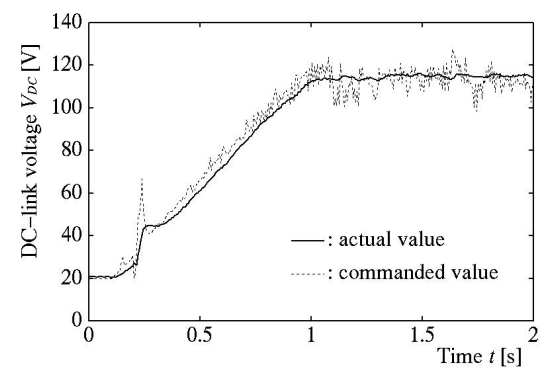

(d)

Fig. 10. Experimental results: high speed operation for variable DC-link voltage.

variable DC-link voltage operation. From Fig. 9, it can be seen that the electric torque, rotor speed and commanded voltage become unsteady and that the motor does not operate properly. This is due to the lack of motor terminal voltage. Fixed DClink voltage can provide a certain level of terminal voltage. However, in high speed operation, it does not get sufficient voltage to operate and therefore limits the motor speed.

Fig. 10 shows the experimental results for high speed operation with a variable DC-link voltage. From these experimental results, it can be seen that the electric torque, rotor speed and commanded voltage become stable. From the bottom figure of Fig. 10 it can be seen that the DC-link voltage is controlled according to the driving condition. During the high speed

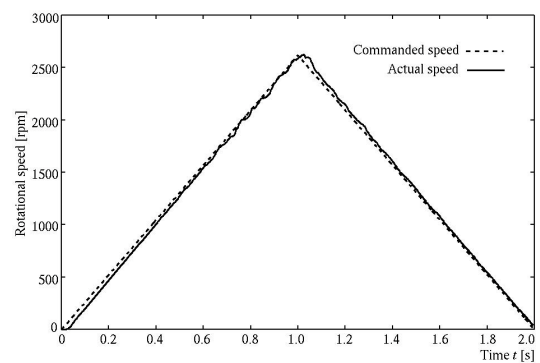

(a)

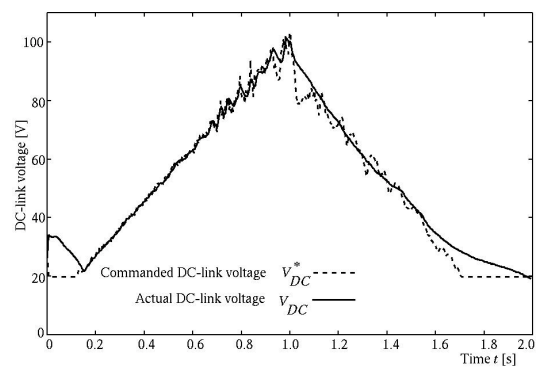

(b)

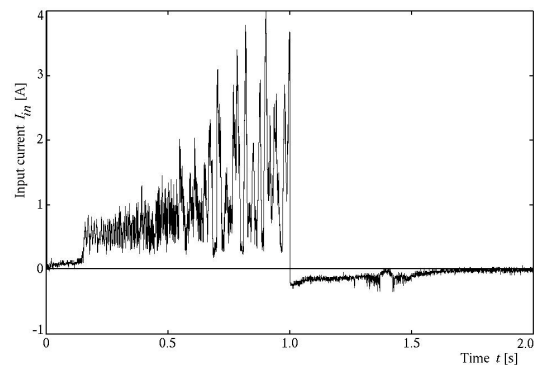

(c)

Fig. 11. Experimental results: during braking operation for variable DC-link voltage.

range of operation, the DC-DC converter is operated in boost mode. From the bottom figure of Fig. 10, it can be seen that the DC-link voltage moves up to $120 \mathrm{~V}$ due to the boost mode operation of the DC-DC converter. As a result, the motor gets enough voltage to operate in the high speed range of operation.

Fig. 11 shows the experimental results for the proposed method in the case of a dynamic braking of operation. From this figure, it is observed that the rotational speed, the DClink voltage and the input current of the converter respond properly during this mode of operation. The input current of the converter is negative during the braking mode of operation, which means that the converter is working as a buck converter.

Fig. 12 shows the experimental results of the converter and inverter efficiency for the proposed method under different load conditions. From this figure, it can be seen that the efficiency does not depend on the load condition. It depends on the different rotational speeds. Table II and Table III also represent the efficiency of the converter and inverter at different speeds, values of $K_{P A M}$ and DC-link voltages. From these tables, it is observed that the efficiency is almost unchanged when the DC-link voltage and the $K_{P A M}$ are changed. However, when the rotational speed is changed, the efficiency varies. 
TABLE I

SPECIFICATION OF MACHINE AND CONTROL PARAMETERS

\begin{tabular}{|c|c|}
\hline \multicolumn{2}{|l|}{ PMSM } \\
\hline Rated power & $160 \mathrm{~W}$ \\
\hline Maximum rated speed & $3000 \mathrm{rpm}$ \\
\hline Rated torque & $0.5 \mathrm{Nm}$ \\
\hline Stator resistance & $2.20 \Omega$ \\
\hline Stator inductance & $6.5 \mathrm{mH}$ \\
\hline Emf constant & $0.0658 \mathrm{~Wb}$ \\
\hline Pole pair & 2 \\
\hline Inertia moment & $1.510^{-4} \mathrm{kgm}^{2}$ \\
\hline \multicolumn{2}{|l|}{ PWM-VSI } \\
\hline Carrier frequency & $5 \mathrm{kHz}$ \\
\hline Dead time & $5 \mu \mathrm{s}$ \\
\hline \multicolumn{2}{|c|}{ Bi-directional DC-DC converter } \\
\hline Inductance & $L=1410 \mu \mathrm{H}$ \\
\hline Input /output capacitor & $C_{1}=C_{2}=80 \mu \mathrm{F}$ \\
\hline \multicolumn{2}{|c|}{ Controllers } \\
\hline Proportional gain for SC & 0.02 \\
\hline Integral gain for $\mathrm{SC}$ & 0.10 \\
\hline Proportional gain for $\mathrm{CC}$ & 10 \\
\hline Proportional gain for $\mathrm{CC}$ & 1000 \\
\hline PAM coefficient & $K_{P A M}=2.5$ \\
\hline Lower limit of DC-link voltage & $V_{D C \min }=20 \mathrm{~V}$ \\
\hline
\end{tabular}

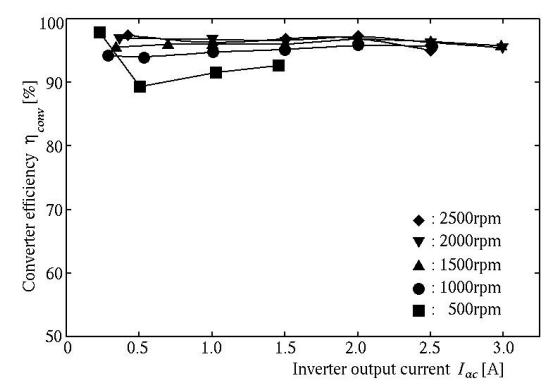

(a)

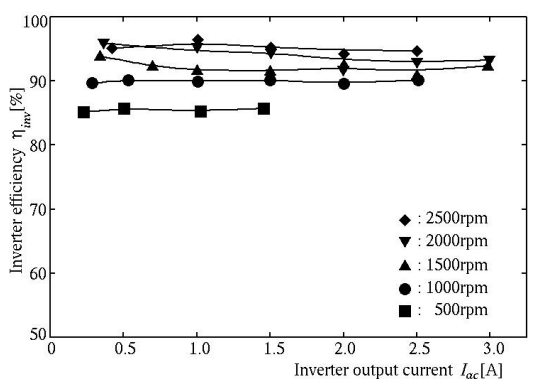

(b)

Fig. 12. Experimental results: Converter and Inverter efficiency for variable DC-link voltage.

\section{CONCLUSIONS}

This paper proposes an optimal PAM control system for PMSM drives which can adjust the PWM-VSI DC-link voltage according to the driving condition in a range from low to high speed. This system uses a bi-directional buck boost DC-DC converter and this paper describes the determining methods for an optimal DC-link voltage and the converter duty factors.

It can be confirmed that the commanded voltages, the armature currents and the produced torque are improved in the low speed range and that the allowable driving range is extended.
TABLE II

EFFICIENCY OF CONVERTER $\eta_{\text {conv }}$ [\%] (AT DIFFERENT SPEEDS, $K_{P A M}$ AND DC-LINK VOLTAGES)

\begin{tabular}{|c|c|c|c|c|}
\hline \multirow{2}{*}{$\begin{array}{c}\text { Rotational } \\
\text { speed } \\
{[\mathrm{rpm}]}\end{array}$} & \multicolumn{3}{|c|}{$K_{P A M}=2.5$} & $K_{P A M}=3$ \\
\cline { 2 - 5 } & \multicolumn{3}{|c|}{ DC-link voltage } & $V_{D C}[\mathrm{~V}]$ \\
\cline { 2 - 5 } & 50 & 80 & 100 & 80 \\
\cline { 2 - 5 } & \multicolumn{3}{|c|}{ Efficiency of converter $\eta_{\text {conv }}[\%]$} \\
\hline 500 & 91.8 & 92.9 & 91.1 & 92.9 \\
1000 & 94.6 & 94.9 & 94.2 & 95.7 \\
1500 & 94.1 & 96.1 & 95.6 & 96.7 \\
2000 & 92.8 & 96.9 & 94.0 & 95.7 \\
2500 & 94.5 & 96.6 & 96.7 & 95.7 \\
\hline
\end{tabular}

TABLE III

EFFICIENCY OF INVERTER $\eta_{\text {conv }}$ [\%] (AT DIFFERENT SPEEDS, $K_{P A M}$ AND DC-LINK VOLTAGE)

\begin{tabular}{|c|c|c|c|c|}
\hline \multirow{4}{*}{$\begin{array}{c}\text { Rotational } \\
\text { speed } \\
\text { [rpm] }\end{array}$} & \multirow{2}{*}{\multicolumn{3}{|c|}{$\frac{K_{P A M}=2.5}{\text { DC-link voltage }}$}} & $K_{P A M}=3$ \\
\hline & & & & $\overline{V_{D C}[\mathrm{~V}]}$ \\
\hline & 50 & 80 & 100 & 80 \\
\hline & \multicolumn{4}{|c|}{ Efficiency of converter $\eta_{\text {conv }}[\%]$} \\
\hline 500 & 84.8 & 85.5 & 84.7 & 84.9 \\
\hline 1000 & 90.4 & 89.9 & 89.8 & 89.9 \\
\hline 1500 & 92.6 & 92.2 & 92.1 & 91.7 \\
\hline 2000 & 93.4 & 93.9 & 94.0 & 93.3 \\
\hline 2500 & 94.1 & 95.1 & 94.6 & 94.1 \\
\hline
\end{tabular}

\section{REFERENCES}

[1] B. K. Bose, "Modern power electronics and AC drives," Prentice- Hall, 2002.

[2] Kim, H.-W. Youn, M.-J. Cho, K.-Y. Kim, H.-S., "Nonlinearity estimation and compensation of PWM VSI for PMSM under resistance and flux linkage uncertainty," IEEE Trans. on Control Systems Technology, Vol 14, No. 4, pp 589-601, 2006.

[3] Kim, H.-W. Youn, M.-J. Cho, K.-Y., "New voltage distortion observer of PWM VSI for PMSM," IEEE Trans. on Industrial Electronics, Vol 52, No. 4, pp 1188-1192, 2005.

[4] F. Blaabjerg, J. K. Pederson, and P. Thoegersen, "Improved modulation techniques for PWM-VSI drives," IEEE Trans. Ind. Electron., Vol. 44 No. 1 pp. 87-95, 1997.

[5] G. Gallegos-Lopez, F. S. Gunawan and J. E. Walters, "Optimum torque control of permanent-magnet $\mathrm{AC}$ machines in the field-weakened region," IEEE Trans. Ind. Applicat., Vol. 41, Issue 4, pp. 1020-1028, Jul./Aug. 2005.

[6] S. Shinnaka, "New practical optimal current control methods for energyefficient wide-speed-range operation of salient-pole permanent magnet synchronous motor with core-losses," IEEJ, Trans. IA, Vol. 123, No. 11, pp. 1359-1370, 2003.

[7] G.D. Marques and P. Verdelho, "A simple slip-power recovery system with a DC voltage intermediate circuit and reduced harmonics on the mains," IEEE Trans. on Industrial Electronics, Vol. 47, Issue 1, pp 123132, Feb. 2000.

[8] Casadei, D. Milanesi, F. Serra, G. Tani, A. Zarri, L., "Control of induction motors for wide speed range for electric vehicle drives," 18th International Conference on ICEM, pp. 1-6, Sep. 2008.

[9] F. Caricchi, F. Crescimbini, F. G. Capponi, and L. Solero, "Study of bidirectional buck-boost converter topologies for application in electrical vehicle motor drives," in Proc. APEC1998, Vol.1, pp. 287-293, Feb. 1998.

[10] N. Urasaki, Y. Noguchi, A.M. Howlader, Y. Yonaha, A. Yona and T. Senjyu, "Wide-speed range operation of interior permanent magnet synchronous motor with parameter identification," Electric Power and Components Systems, Vol. 37, Issue 8, pp. 847-865, Aug. 2009.

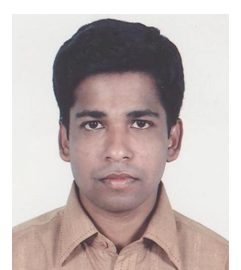

Abdul Motin Howlader was born in Munshiganj, Bangladesh. He received his B.S. in Computer Science and Engineering from the United International University, Dhaka, Bangladesh. Currently, he is a Master's student in the Electrical and Electronics Engineering department at the University of the Ryukyus, Japan. Mr. Motin is the student member of IEEE, IEEJ and IEICE. 


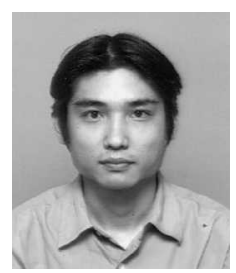

Naomitsu Urasaki was born in Okinawa Prefecture, Japan in 1973. He received his B.S. and M.S. in Electrical Engineering from the University of the Ryukyus, Japan, in 1996 and 1998, respectively. Since 1998, he has been with the Department of Electrical and Electronics Engineering, Faculty of Engineering, University of the Ryukyus, where he is currently an Associate Professor. His research interests are in the areas of modeling and control of ac motors. Mr. Urasaki is a Member of the IEEE and the Institute of Electrical Engineers of Japan.

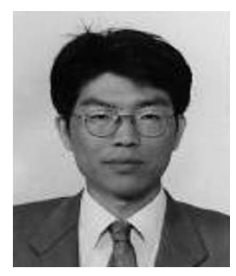

Tomonobu Senjyu was born in Saga Prefecture, Japan, in 1963. He received his B.S. and M.S. in Electrical Engineering from the University of the Ryukyus, Okinawa, Japan, in 1986 and 1988, respectively, and his $\mathrm{Ph} . \mathrm{D}$. in Electrical Engineering from Nagoya University, Nagoya, Japan, in 1944. Since 1988, he has been with the Department of Electrical and Electronics Engineering, Faculty of Engineering, University of the Ryukyus, where he is currently a Professor. His research interests are in the areas of stability of ac machines, advanced control of electrical machines, and power electronics. Prof. Senjyu is a member of the IEEE and the Institute of Electrical Engineers of Japan.



Atsushi Yona was born in Okinawa, Japan, in 1982. He received his B.S., M.S. and Ph.D. from the University of the Ryukyus, Okinawa, Japan, in 2006, 2008, and 2010, respectively, all in Electrical Engineering. In 2008, he joined the University of the Ryukyus, where he is now an Assistant Professor. His research interests include wind generators, photovoltaic generators, and forecasting techniques. Dr. Yona is a member of the IEEE and the Institute of Electrical Engineers of Japan.

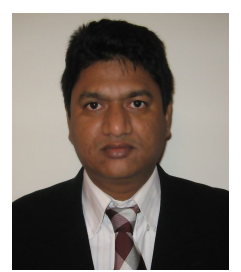

Ahmed Yousuf Saber was born in Rajshahi, Bangladesh. He received his B.S. and M.S. from the Bangladesh University of Engineering and Technology, Dhaka, Bangladesh, and his Ph.D. from the University of the Ryukyus, Okinawa, Japan in 2007. Dr. Saber was a Post-doctoral Fellow at Toyota Technological Institute, Japan. He served as an Assistant Professor at The University of Asia Pacific, Dhaka, Bangladesh and at the King Abdulaziz University, (KAU) Jeddah, Saudi Arabia. He is currently working as a Visiting Scholar at the Missouri University of Science and Technology, Rolla, MO, USA. 